\title{
Automatic Load Disconnection and Reconnection to Power System using Controllable Loads
}

\author{
K Hareesh ${ }^{1}$ | A Siva Satya Reddy ${ }^{1}$ Ch Dinesh $^{1} \mid$ Imran Abdul ${ }^{1}$ \\ ${ }^{1}$ Department of Electrical and Electronics Engineering, Laki Reddy Bali Reddy College of Engineering, Mylavaram, India.
}

To Cite this Article

K Hareesh, A Siva Satya Reddy, Ch Dinesh and Imran Abdul, "Automatic Load Disconnection and Reconnection to Power System using Controllable Loads", International Journal for Modern Trends in Science and Technology, Vol. 06, Issue 06, June 2020, pp.:115-120; https://doi.org/10.46501/IJMTST060625

\section{Article Info}

Received on 12-May-2020, Revised on 04-June-2020, Accepted on 07-June-2020, Published on 15-June-2020.

\section{ABSTRACT}

Now a days, Renewable Energy Resources are playing a vital role in power system to meet the demand. As Renewable Resources includes solar power, Wind power generation they are eco-friendly in the aspect of power generation. It is progress a step forward to integrate the renewable power along with base load plants such as Thermal power plant. With the advancement in the network Technology, smart meters had became the key components in maintaining the power system to behave smartly by the demand side management.

On the other hand, the sudden loss of Generation due to natural calamities like cyclones, will become a great burden on the power system. And thus the power system will try to be out of synchronization and leads to the problem of unstable. This is because of high penetration of Renewable power source like solar, wind etc...in to the Grid. Hence this type of scenario results in BLACKOUT of the power system which means the whole power system is going to be shut down and the whole world will remain in the darkness.

To avoid the above situation, Demand Side Management is the best solution which is possible with controllable loads and load controller together called as Smart meter. This will play a key role is retaining the system frequency and LOAD FREQUENCYCONTROL will be improved further. In this project, we are going to simulate the simulink model of power system LOAD FREQUENCY CONTROL WITH CONTROLLABLE LOADS in MATLAB

KEYWORDS: load frequency control, renewable energy sources, automatic load connection and disconnection

Copyright (C) 2014-2020 International Journal for Modern Trends in Science and Technology DOI: https://doi.org/10.46501/IJMTST060625

\section{INTRODUCTION}

Investigation of load control to provide frequency response using smart meters" is proposed by samarkoon and Nick Jenkins to achieve frequency control by implementing the smart meters in the power system network. The improvement in the brilliant Grid innovation can change the customary situation of intensity framework control. In this paper they talked about the harmony between the generation and burden .If an unexpected loss of power happens, or an abrupt difference in power yield of inexhaustible sources prompts quick deveation in system frequency.

In order to maintain the frequency, they proposed frequency response services such asFFR(Firm frequency response) and FCDM(Frequency control Demand Management).These services are liable for holding the recurrence .If frequency drops or increments out of nowhere, the heap ought to get detached from the matrix so as to maintain a strategic distance from shutdown of intensity framework 
.Use of brilliant meters for the above capacity can yeild great outcomes for appropriate working of intensity system.

Controllable load management approaches in Smart Grids" is proposed by shen, Jiang and bosong $\mathrm{Li}$ where the load management is achieved by the Controllable loads. The efforts in this project helps mainly the customer to participate in the Demand side management .The controllable loads can broadly categorised in to Active and Passive ones.Washing machines, refrigirators, hair dryers ,inline heaters, etc..... falls under the category of passive one.V2G, heat storage fall under the active controllable loads . They are having a lot advantages such as peak shaving, load balance, frequency regulation and voltage stability .Added to this they can provide fast balancing services to renewable energy grid in the distributed power system.

Emerging Smart meters in Electrical distribution system"-proposed by Jamali ,Estebsari, Enrico pons and Bompard discussed about the New type of smart meters which can satisfy more objectives of the customer such as providing detailed consumption information, allowing load scheduling, real time electricity pricing, advanced outage management system, etc......They discussed about the two way communication between the customer and the provider with the help of Internet and cloud communication systems .It Enhances the load frequency control in better way than the conventional frequency control measures.

\section{LOAD FREQUENCY CONTROL}

Automatic generation control (AGC) is a framework for altering the powergeneration of numerous generators at various power stations, because of changes in the load. There are two important parameters in power system continuously to be monitored and adjusted according to the load. They are 1.Voltage and 2.Frequency.

These are to be adjusted when there is mismatch between the load and demand. Voltage needs to be adjusted when generated reactive power is not equal to absorbed reactive power i.e. $\left(Q_{g e n} \neq\right.$

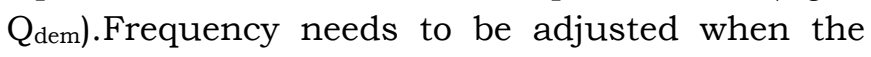
generated active power $\left(\mathrm{P}_{\text {gen }}\right)$ is not equal to demanded active power $\left(\mathrm{P}_{\mathrm{dem}}\right)$.

There are two mechanisms to control $\mathrm{v}$ and f.They are
1.Primary control Mechanism.2.Secondary control Mechanism.

Automatic Generation Control=Load Frequency Control (LFC) + Excitation control.

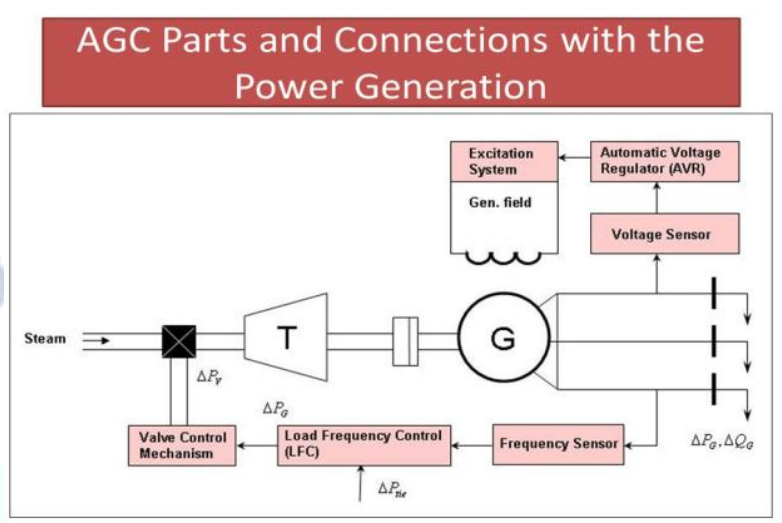

Fig : 3.1 Automatic Generation Control

\subsection{NEED OF LOAD FREQUENCY CONTROL.}

The dynamic and responsive power demands are infrequently predictable and they continually changes with the rising or falling of load demand. There will be a problem of asynchronous with thesuddenchange in load which causes issues.

Most AC motors run at speeds that are truly related to synchronous. The speed and started electro method of reasoning force (e.m.f) may vacillate because of the distinction in repeat of the power circuit. While working at frequencies beneath $49.5 \mathrm{~Hz}$; a few kinds of steam turbines, certain rotor states experience unreasonable vibration. The alteration in repeat can cause mal movement of intensity converters by making music. For power stations running in equivalent it is significant that repeat of the framework must remain consistent for synchronization of generators.

\subsection{SPEED GOVERNING MECHANISM.}

The speed administering system incorporates the accompanying parts.

Speed Governor: It is a blunder detecting gadget in load recurrence control. It incorporates all the components that are straightforwardly receptive to speed and impact different components of the framework to start activity.

Governer Controlled Valves: They control the contribution to the turbine and are activated by the speed control component.

Speed Control MechanismIt incorporates all gear, for example, switches and linkages, servomotors, intensifying gadgets and transfers that are set between the speed senator and the representative controlled valves. 
Speed Changer :It empowers the speed senator framework to change the speed of the turbo generator unit while in activity.

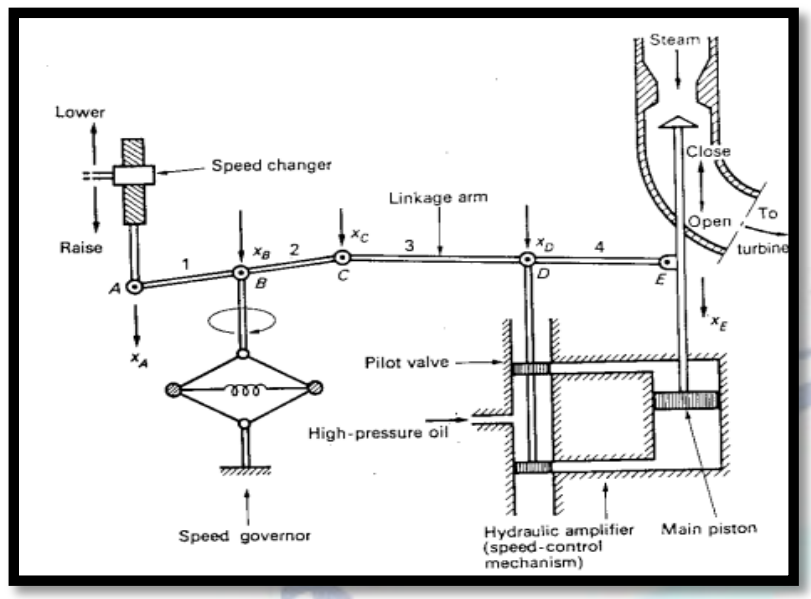

Fig:3.2. Speed Governing Mechanism.

\subsection{SINGLE AREA LOAD FREQUENCY CONTROL.}

Basically, single zone power system involves a representative, a turbine, and a generator with contribution of rule reliable. System in like manner consolidates step load change commitment to the generator. This work in a general sense, related with the controller unit of a single zone power system. The stack repeat control systems have been proposed subject to the standard direct Control speculation. These controllers may be unsuitable in some working conditions due to the multifaceted idea of the power systems, for instance, nonlinear weight characteristics and variable working core interests. To specific makers, variable structure control keeps up sufficiency of system repeat. In any case, this procedure needs a few information for system states, which are difficult to know completely. Also, the growing needs of stunning and enormous current power structures require perfect and versatile action of them. The dynamic and static properties of the system must be prominent to structure a beneficial controller

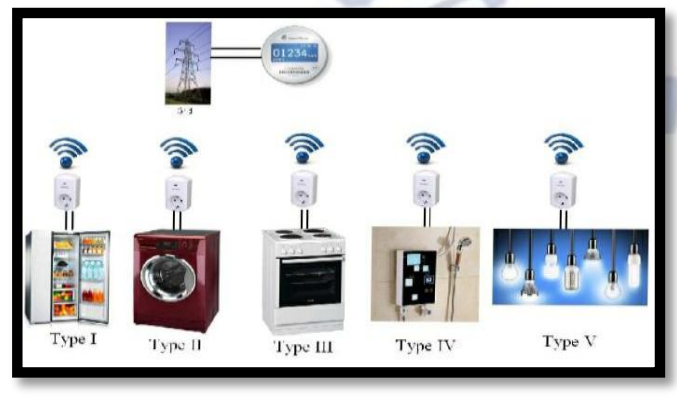

III. CONTROLLABLE LOADS

Controllable loads can be defined as "the loads which allows control up on them from the source side."

\subsection{CONTROLLABLE LOADS}

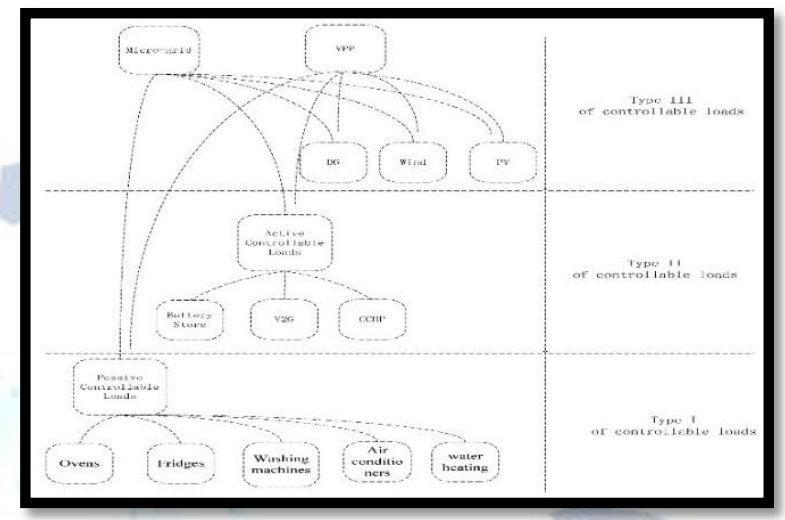

Fig:Smart meter with controllable loads

The controllable loads are requested into three sorts, Type I, Type II and Type III. Type I fuses private, Types II fuses Vehicle-to-Grid (V2G), battery storing and joined warmth and power (CHP) units, and Type III fuses the Micro syst., and the virtual power plants. In the astute meter is proposed to measure the repeat and take part in the load repeat control. As demonstrated by the stores are separated into five get-togethers.

\subsection{TYPES OF CONTROLLABLE LOADS.}

Controllable loads incorporate a more extensive territory than the customary ones. Different kinds of controllable burdens are characterized as follows:

\section{3. .LOAD CONTROLLER.}

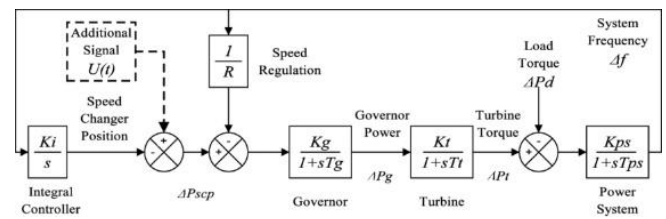

The ALC Automatic Load Controller is an incorporated piece of DEIF power the executives frameworks. If there should be an occurrence of generator drive when the mains network can't, it might be important to control the framework load. At the point when the ALC is set in an area of the framework, it will be fit for controlling up to 8 shopper feeder breakers.

The switching frequencies and the timing of the loads control is given below :Table Timing and Switching Frequencies of Load Controller. 


\begin{tabular}{|l|c|c|c|c|c|c|c|}
\hline & $\begin{array}{c}F_{\text {OFF, }}, \\
\mathrm{Hz}\end{array}$ & $\begin{array}{c}F_{\text {ON }}, \\
\mathrm{Hz}\end{array}$ & $\begin{array}{c}T_{\text {OFF }}, \\
(\mathrm{s})\end{array}$ & $\begin{array}{c}T_{M}, \\
(\mathrm{~s})\end{array}$ & $\begin{array}{c}T_{D}, \\
(\mathrm{~s})\end{array}$ & $\begin{array}{c}T_{R}, \\
(\mathrm{~s})\end{array}$ & $T_{T}$, \\
\hline Type I & 49.7 & 49.8 & 30 & 150 & 90 & 30 & $\begin{array}{c}5 \\
\mathrm{~min}\end{array}$ \\
\hline Type II & 49.5 & 49.7 & 30 & 90 & 60 & 30 & $\begin{array}{c}3.5 \\
\mathrm{~min}\end{array}$ \\
\hline Type III & 49.3 & 49.5 & 30 & 30 & 30 & 30 & $\begin{array}{c}2 \\
\mathrm{~min}\end{array}$ \\
\hline Type IV & 49.0 & $\mathrm{NA}$ & 10 & 0 & 0 & 5 & $\begin{array}{c}15 \\
(\mathrm{~s})\end{array}$ \\
\hline Type V & 48.9 & NA & 2 & 0 & 0 & 2 & $\begin{array}{c}4 \\
(\mathrm{~s})\end{array}$ \\
\hline
\end{tabular}

\section{MATLAB SIMULATION AND RESULTS.}

\section{BLOCK DIAGRAM OF POWER SYSTEM.}

A Simulink block diagram model is a graphical representation of a scientific model of a unique framework. A numerical model of a powerful framework is depicted by a lot of conditions. The scientific conditions portrayed by a square chart model are known as mathematical, differential, as well as contrast conditions.

The square outline of warm force framework can be extensively devided in to two sections. They are Power framework and controllable burden. Force framework part contains the squares of Governor, Turbine, Generator, step which is utilized as loss of age and Integral controller. Controllable burden contains load controller which uses to disengage and reconnect the heaps to the framework dependent on Frequency of the Power framework. It likewise contains defer square to sit tight for at some point which is called as checking period to disengage or reconnect the load to the system.

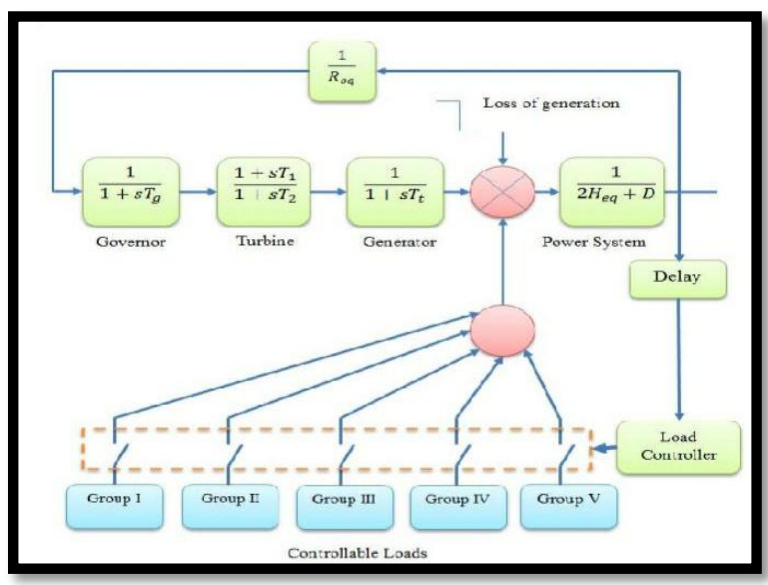

Fig : Block diagram of power system.

Where Tg is the representative time steady which rises to $0.2 \mathrm{~s}, \mathrm{~T} 1$ and $\mathrm{T} 2$ are the time maintain constants of the lead-slack compensator which equivalent $2 \mathrm{~s}$ and $12 \mathrm{~s}$ individually, Req is the addition of the senator hang control which rises to 0.0909, Tt is the turbine time consistent which equivalent $0.3 \mathrm{~s}, \mathrm{D}$ is the damping steady $\mathrm{Heq}$ is the identical dormancy from the Great Britain power system which is equal to $9 \mathrm{~s}$.

\subsection{SIMULINK MODEL}

a) Simulation of power system without loads.

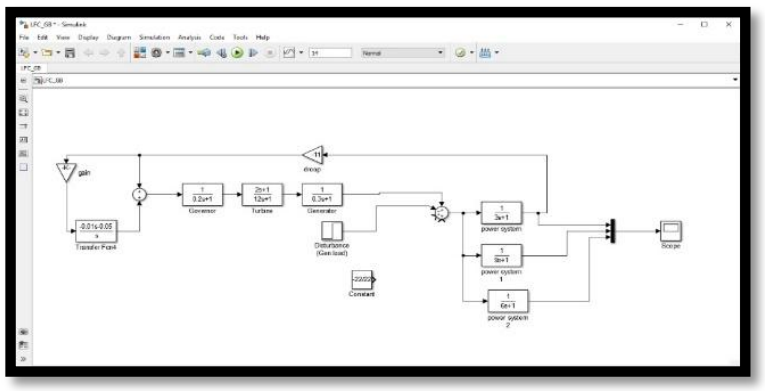

Fig: Single area load frequency control.

The above SIMULINK model shows the power system for single area. It consists of transfer functions of Governor, Turbine, Generator and power system which is a function of sudden loss of generation and hence Frequency. The diagram consists step inputs which represents the disturbances in the system. As the step value increases, the disturbance also increases. The system is controlled by a PI Controller whose $\mathrm{Kp}$ and Ki values are 0.01 and 0.05 respectively. The scope is used for monitoring the variations of Frequency curve from actual Frequency.

The frequency response with different loss generation and inertia is shown in Fig. 5.3. We have selected a $2.5 \mathrm{GW}$ loss of generation as a worst case scenario. From Fig. 5.3, this generation loss could result in activating wide range load shedding, especially with the loss of $2.5 \mathrm{GW}$ of generation which speculated to be caused by the wind turbines.

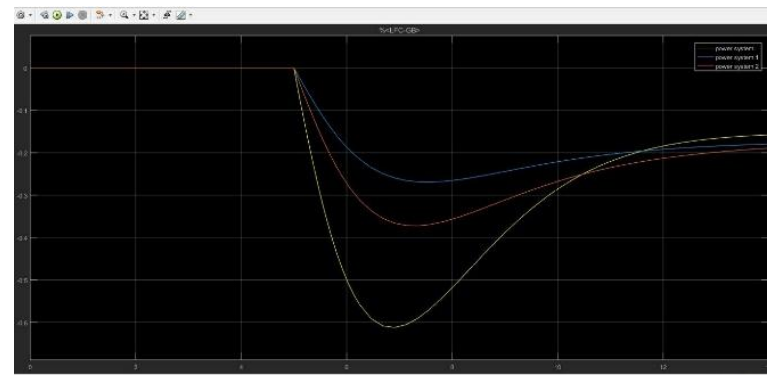

Fig : Frequency response for different loss of generation. 
The response indicates that, for different loss of generations, the corresponding Frequency is changing. If the loss of generation is high then the deviation in the Frequency also increases. The above response is without controllable loads. If the loads are connected then the response is going to be improved than before.

\section{b) Simulation after connecting controllable loads.}

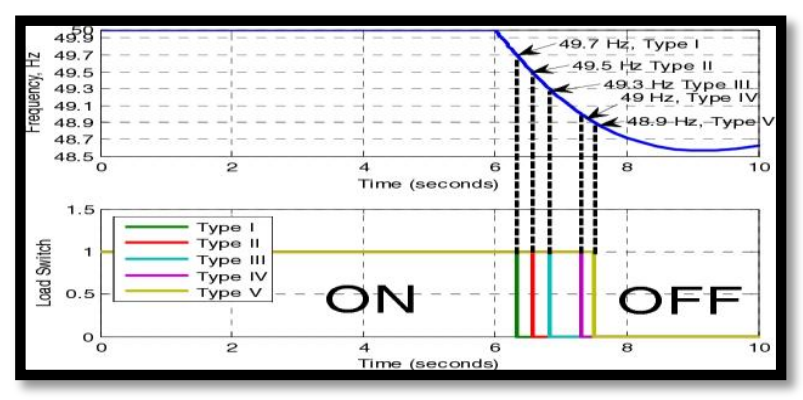

In this SIMULINK diagram, Controllable loads are connected to improve the stability and performance of the power system. It consists of delay block to wait for some time to disconnect or reconnect the loads to the system based on Frequency of Load

When the above SIMULINK diagram is run, then the results of the Simulation is shown in Fig.5.5. It shows the Frequency deviations of the power system when the Controllable loads are connected and not connected. We can observe that theFrequency deviation is less in case of when Controllable load is connected than that of not connected.

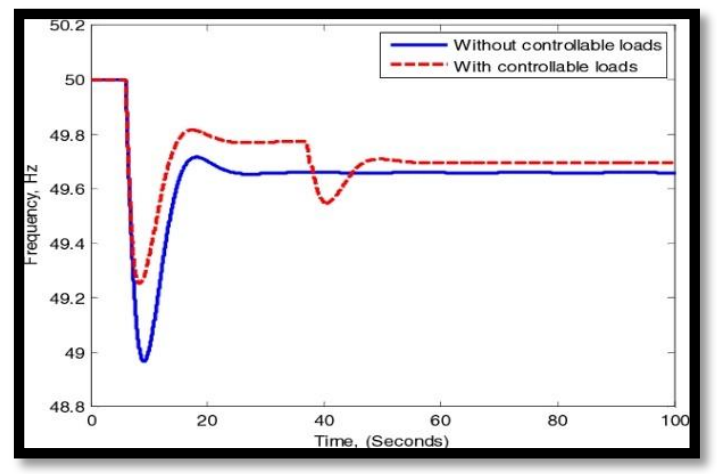

Fig : Frequency deviation with and without controllable loads.

\section{c) Automatic Disconnection and Reconnection of loads.}

A simulation for the load controllers is done to approve their activity. Fig. 5.6. shows the recurrence reaction with $2.5 \mathrm{GW}$ loss of age and $3 \mathrm{~s}$ comparable latency alongside the load exchanging. Type I, II and III burdens are the non-basic load and they are the first to be separated from the system due to their high switch-off frequency. As the frequency drops more loads are disconnected. The inline heater and the lights are the last loads to be associated. After the predefined blocking time the piles are reconnected depending upon their switch on repeat as showed up in Fig.. The lighting and the in-line radiators have the most restricted blocking time. Type I, II and III holds on for 2 min to $5 \mathrm{~min}$ to reconnect. In the event that the recurrence recoups during the checking time the heaps can be reconnected consequently.

The results have shown that, the loads are getting disconnected from the system in a prioritised manner. The priority is based upon the switch off Frequency of various load. It is operated by the load controller inside the Controllable loads. The load Controller disconnects the load when the Frequency drops below the minimum maintained Frequency of the load. This reduces the burden on the system in the emergency conditions and improves the performance and stability of the system. However for sudden loss of generation, Frequency will drop slightly. But the time to recover or to maintain normal Frequency will be less.

Fig: Automatic Disonnection of loads.

In the above figure it shows that the loads are

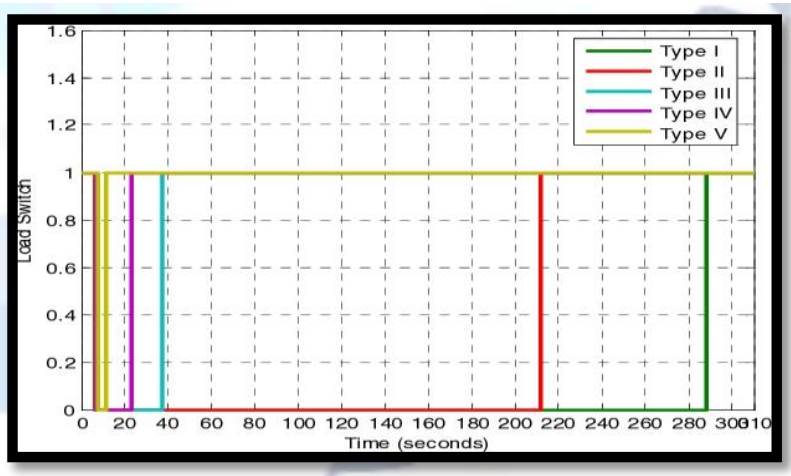

getting reconnected to the system based on their switch on Frequency. Whenever the system attains normal Frequency, it is the load controller which is responsible for the Reconnection of loads to the power system.

\section{CONCLUSION}

With the great penetration of renewable power, mainly the wind and solar power, the generation loss is very high. Smart meters can play great role as control units at the demand side. The paper presents the model of controllable loads and the 
smart meter for studies of load frequency controllingsystem. A Simulink model for the load frequency with the controllable load is crucial. The controllable loads are classified into five types depending on their performance characteristics. From the simulations the controllable loads can greatly enhance the performance of the load frequency control system. As the controllable act faster than the conventional generators they can prevent from the uncertain load shedding.

\section{REFERENCES}

[1] Janaka Ekanayake Kamalanath Samarakoon, "Demand side primary frequency response support through smart meter control", The 44th International Universities Power Engineering Conference (UPEC), 2009,pp.1-5.

[2] A. Khalil and J. Wang, "Stabilization of load frequency control system under networked environment," 2015 21st International Conference on Automation and Computing (ICAC), Glasgow, 2015, pp.1-6.

[3] Chuanwen Jiang, Bosong Li Jingshuang Shen, "Controllable Load Management Approaches in Smart Grids," Energies, vol. 2015, no. 8, pp. 11187-11202,2015.

[4] Janaka Ekanayake, Nick Jenkins Kamalanath Samarakoon, "Investigation of Domestic Load Control to Provide Primary Frequency Response Using Smart Meters," IEEE Transactions on Smart Grid, vol. 3, no. 1, pp. 282-292,2012. 